\section{Early Generation Selection within a Diploid Hybrid Solanum tuberosum Groups Phureja and Stenotomum Population for the Intense Yellow-flesh Creamer Potato Market}

\author{
Kathleen G. Haynes \\ United States Department of Agriculture-Agricultural Research Service, \\ Genetic Improvement of Fruits and Vegetables Laboratory, Beltsville, MD \\ 20705
}

\author{
Lincoln Zotarelli and Christian T. Christensen \\ Horticultural Sciences Department, University of Florida, Gainesville, FL \\ 32611
}

Stephanie Walker

Extension Plant Sciences, New Mexico State University, Las Cruces, NM 88003

Additional index words. carotenoids, lutein, nutrition, tuber appearance, tuber dormancy, tuber eye depth, tuber shape, tuber skin color, tuber skin texture, zeaxanthin

\begin{abstract}
Consumer demand for specialty market potatoes has been growing. Cultivated South American diploid potatoes possess great variation for skin and flesh colors, shape, and taste. A long-day adapted population of Solanum tuberosum groups Phureja and Stenotomum (phu-stn) was evaluated for characteristics associated with the type known as papa criolla or papa amarilla in South America. Tubers have intense yellow flesh and may be fried or roasted and eaten whole. A U.S. northern location (Maine), representative of a seed growing region, and two southern locations (Florida and New Mexico), representative of potato growing regions near large Hispanic populations, evaluated yellow-fleshed clones selected within a phu-stn population. Agreement between selectors at two locations was greater than $50 \%$. Tuber skin color and shape were highly correlated between locations; flesh color and tuber dormancy moderately so; eye depth had low correlation between locations; and appearance and skin texture had low or no correlation between locations. Tuber dormancy was generally short, but a few longer dormant clones were identified. There were significant differences among clones for yields, with the highest yields occurring in Maine. More intense evaluations are planned for a subset of these clones before possible release as new varieties. Future breeding efforts will be undertaken to lengthen tuber dormancy in this population.
\end{abstract}

Potatoes are the most widely consumed vegetable in the United States (USDA, ERS, 2013). Most U.S. potato cultivars are white fleshed, although several yellow-flesh cultivars have also met with considerable consumer acceptance, and more recently, red-and purple-flesh cultivars have been released (Potatoes USA, 2018). The consumption of processed potato products (mainly chips and fries) and fresh market potatoes (mainly round whites for boiling and russets for baking) has been fairly stable (USDA,

Received for publication 14 Sept. 2018. Accepted for publication 11 Sept. 2019.

K.G.H. is a Research Geneticist.

L.Z. is an Associate Professor.

C.T.C. is a former Graduate Research Assistant.

S.W. is an Extension Vegetable Specialist.

L.Z. is the corresponding author. E-mail: lzota@ ufl.edu.
Stenotomum, and specifically to a hybrid population of these two groups bred for long-day adaptation to the United States (Haynes, 1972, 2008), hereinafter referred to as phu-stn.

High levels of carotenoids have been reported in the long-day adapted phu-stn population ( $\mathrm{Lu}$ et al., 2001). Carotenoids may protect against a variety of chronic diseases including cardiovascular disease and certain cancers. Perhaps the clearest link between specific carotenoids and a health outcome is that for lutein/zeaxanthin and age-related macular degeneration (Snodderly, 1995) and reduction of inflammation and DNA damage in heathy adults (Kaspar et al., 2011). More recently better mental health performance in the elderly has been linked to lutein and zeaxanthin (Akbaraly et al., 2007; Feeney et al., 2017; Johnson, 2012; Vishwanathan et al., 2014). High concentrations of lutein exist in darkgreen, leafy vegetables, which are consumed in low amounts. Zeaxanthin is less abundant in most vegetables (Sommerburg et al., 1998). Thus, increasing the amounts of these carotenoids in a widely consumed vegetable, such as potato, may offer significant health benefits.

Lutein and zeaxanthin are produced on two separate branches of the carotenoid biosynthetic pathway (Diretto et al., 2006). The yellow-fleshed trait is the result of a dominant allele of beta-carotene hydroxylase, designated Chy 2 allele 3 by Wolters et al. (2010) or Bch by Brown et al. (2006). A recessive allele of zeaxanthin epoxidase, denoted Zep1, results in an accumulation of zeaxanthin, which imparts the orange-flesh trait in potatoes (Wolters et al., 2010). McCord et al. (2012) found that tetraploids with zero, one, or two copies of the Zepl allele had similar levels of zeaxanthin; triplex individuals had slightly higher concentrations; and, individuals homozygous for Zepl had the highest levels.

Potatoes are eaten in many different ways, and cooking method can have a large impact on carotenoid composition in the cooked product. Although carotenoid concentrations in boiled potatoes are lower than in raw potatoes (Blessington et al., 2010; Tierno et al., 2015), lutein and zeaxanthin concentrations are unaffected by boiling (Burgos et al., 2012). Lutein and zeaxanthin have even been reported to be higher following steaming or microwave cooking (Clevidence et al., 2005), suggesting that these carotenoids may have been released from the potato matrix. Kotiková et al. (2016) reported that boiled yellow-flesh potatoes retained $76 \%$ to $81 \%$ of their lutein, whereas baked yellowfleshed potatoes retained $57 \%$ to $60 \%$ of their lutein. Total and individual carotenoid concentrations have been reported to vary considerably among potato accessions that have been boiled (Burgos et al., 2012), suggesting that there is an important genetic component to the cooking response.

The high carotenoid diploid potatoes we have developed have potential as a new 
specialty market potato for the intense yellow-flesh creamer potato market. Their high carotenoid content and unique flavors should appeal to South American Hispanics (because the potatoes are like the papa criolla or papa amarilla cultivars of South America) and to health-conscious consumers, who associate color with nutritional benefits.

In this work, we report on the results of early generation selection studies within a diploid phu-stn population for the intense yellow-flesh creamer market at three locations in the United States: a southeastern (Florida), southwestern (New Mexico), and a seed production environment (Maine). Tuber characteristics evaluated in the first and second field generation in each environment were tuber skin color, skin texture, shape, eye depth, appearance, flesh color, and length of dormancy. In each environment, clonal selections were made for future evaluations, and the agreement among selectors was compared.

\section{Materials and Methods}

On 12 May 2012, 71 orange-flesh diploid potato clones from the long-day adapted $\mathrm{phu}$ stn high specific gravity (Haynes, 2008) or late blight resistant (Haynes et al., 2014) populations were planted in a seed nursery on Aroostook State Farm in Presque Isle, ME and allowed to randomly intermate. On the same date, 76 yellow-flesh diploid clones were planted in a separate seed nursery on Aroostook State Farm and allowed to randomly intermate. Both seed nurseries were planted as a randomized complete design with two replications. Six tubers for each clone were planted in a plot in each replication. Plants were rogued visually for Potato virus $Y$ in July 2012. Open-pollinated fruit were collected on 29 Aug. 2012 from 44 orange-fleshed and 45 yellow-fleshed clones, and botanical seed was extracted. On average, $>6500$ seeds were collected from each orange-fleshed clone and $>4600$ seeds from each yellow-fleshed clone.

In the fall of 2013, 200 seeds from each orange- and yellow-fleshed clone were planted in the greenhouse in Island Falls, ME or Beltsville, MD. About $90 \mathrm{~d}$ after transplanting the seedlings into $0.10 \mathrm{~m}$ square pots, the largest tuber from each plant was harvested, bulked by family (i.e., female parent), and placed into cold $\left(4^{\circ} \mathrm{C}\right)$ storage.

First field generation in Maine (2014). On 30 May 2014, these tubers were planted contiguously in the field on Chapman Farm

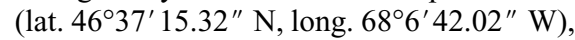
in Mapleton, ME, on a Caribou gravelly loam soil (fine-loamy, mixed, frigid Typic Haplorthod) at an elevation of $200 \mathrm{~m}$ above sea level. Plants were spaced $0.91 \mathrm{~m}$ apart in the row to allow separation at harvest by a onerow digger. Rows were also spaced $0.91 \mathrm{~m}$ apart. Common commercial practices regarding fertilization and pesticide application were followed. No irrigation was available.
At harvest, teams of breeders and agronomists went through the field and made selections based on horticultural characteristics of the tubers, such as smoothness, lack of sprouting, and size. Tubers were rated for skin color, skin texture, shape, eye depth, overall appearance, and flesh color according to the rating scale in Table 1 . Tubers from each clone selected were put into red mesh bags, labeled with the family identification, and then all bags of tubers selected from each family (i.e., female parent) were put together into a wooden box. From 14,035 single hills, 689 clones were initially selected.

The 89 boxes (one for each family) were placed in storage. Beginning 26 Sept. 2014 and weekly thereafter, the bags were examined for tuber sprouting. Bags with sprouted tubers were discarded until only five bags remained for each family. In some cases, the families had fewer than five selections (i.e., bags) to start with, and these were saved. This was done so to initiate a recurrent selection scheme to lengthen tuber dormancy in this material (not part of this study). In all, 357 clones were saved for additional evaluation. Tubers from the saved clones were divided equally three ways: up to four tubers, where available, were sent to Florida and New Mexico, and kept in Maine.

First year field evaluations in the south (2015). Field evaluations were conducted in the spring of 2015 at the University of Florida, Hastings Agricultural Extension Center in Hastings, FL (lat. 29 $9^{\circ} 1^{\prime} 27.58^{\prime \prime}$ $\mathrm{N}$, long. $81^{\circ} 26^{\prime} 31.37^{\prime \prime} \mathrm{W}$ ) at an elevation of $8 \mathrm{~m}$ above sea level. The soil at the field trial location is classified as sandy, siliceous hyperthermic Arenic Ochraqualf belonging to the Ellzey series. On 19 Dec. 2014, the trial area was fumigated with Telone ${ }^{\circledR}[1,3$ Dichloropropene $(63.3 \%)+$ Chloropicrin (34.7\%) C-35; Dow AgroScience; Indianapolis, IN] at a rate of $103 \mathrm{~L} \cdot \mathrm{ha}^{-1}$ and raised rows $(0.35 \mathrm{~m}$ height $)$ were formed with $1.0 \mathrm{~m}$ spacing between rows. On 6 Feb. 2015, tubers were planted in a completely randomized design with one replication on a $0.20 \mathrm{~m}$ in-row spacing. Irrigation was supplied via seepage irrigation. Fertilizer practices follow the guidelines of the Vegetable Production Handbook for Florida (Zotarelli et al., 2012). Plants were vine-killed on 18 May 2015 with a single application of the chemical desiccant glufosinate ammonium (Rely® 280 Herbicide; Bayer Crop Science, Research Triangle Park, NC) applied at a rate of $1,535 \mathrm{~mL} \cdot \mathrm{ha}^{-1}$. Tubers were mechanically harvested using a one-row digger on 1 June 2015. After harvest, tubers were immediately washed and graded into marketable and culls (e.g., mechanical injuries, rotten). A total of 12 marketable tubers were put into mesh bags and maintained a dark, cold room at $10{ }^{\circ} \mathrm{C}$ and $80 \%$ to $85 \%$ relative humidity. Tubers were then weekly evaluated for sprouting.

The New Mexico trials were conducted at New Mexico State University's Los Lunas Agricultural Science Center (lat. $34^{\circ} 46^{\prime} 9.63^{\prime \prime} \mathrm{N}$, long. $106^{\circ} 45^{\prime} 33.09^{\prime \prime} \mathrm{W}$ ), located about $43 \mathrm{~km}$ south of Albuquerque,
$\mathrm{NM}$ at an elevation of $1475 \mathrm{~m}$ above sea level. Although potatoes are a major crop in the northwest area of New Mexico, they are not widely grown in the central to southern part of the state. However, there is great interest in the crop, particularly if cultivars that are high performers in the warmer, southern areas can be identified, providing impetus for testing these clones in Los Lunas. In 2015, four plants per clone were planted per plot at a spacing of $0.23 \mathrm{~m}$ between plants. Spacing between rows was $0.91 \mathrm{~m}$. Plots were furrow irrigated and fertilized in accordance with common practices for other Solanaceous crops grown in the area. Clones were planted on 2 Apr. and harvested on 6 July 2015. For harvest, the tubers were dug up with a one-row, tractor-propelled potato digger. All tubers were picked up and bagged by hand to obtain a total harvest weight for each plot. A 10-tuber sub-sample was taken for each line and placed in storage for longterm sprouting evaluation.

At both locations, tubers were evaluated for skin color, skin texture, shape, eye depth, appearance, and flesh color. Correlations were calculated among locations (ME 2014, FL 2015, NM 2015) for the tuber traits evaluated. The numbers of clones selected at two or more locations were counted; and the percent agreement, determined as the number of clones both locations agreed to save or agreed to discard, among locations was calculated.

Second field generation in Maine (2015). Clones were planted in a completely randomized design on Chapman Farm, Mapleton, ME on 8 June 2015. Plots consisted of four plants per clone. Plants were spaced $0.23 \mathrm{~m}$ within the row, with $0.96 \mathrm{~m}$ between plots in a row, in rows spaced $0.91 \mathrm{~m}$ apart. Common commercial practices were once again used. Plots were harvested on 22 Sept. 2015. Following harvest, 135 clones were selected to continue evaluation; however, all clones were harvested because ME was the seed source for all locations.

Second year field evaluations in the south (2016). The second year field evaluation was conducted in the same area in Hastings, FL. Fertilizer, fumigant, and herbicides were applied at the same rate as the previous year. The experimental area was fumigated on 21 Dec. 2015 and the trial was planted on $2 \mathrm{Feb}$. 2016. Clones were planted in a randomized complete block design with two replications. In-row plant spacing was $0.30 \mathrm{~m}$ and spacing between rows was $1.0 \mathrm{~m}$. Plants were vine-killed on 26 Apr. 2016 and harvested on 10 May 2016. Tuber evaluation and storage conditions were identical to the 2015 season.

The trial was repeated in Los Lunas, NM in 2016; however, additional material was available, so most plots were planted with five tubers, and duplicate plots were planted for most accessions. Similar field management and harvest protocols to the previous year's test were implemented. In 2016, clones were planted on 23 Mar. and harvested on 30 June. 
Table 1. Rating scale for tuber characteristics.

\begin{tabular}{|c|c|c|c|c|c|c|}
\hline Rating & Flesh color & Skin color & Skin texture & Tuber shape & Eye depth & Overall appearance \\
\hline 1 & White & Purple & Partial russet & Round & Very deep & Very poor \\
\hline 2 & Cream & Red & Heavy russet & Mostly round & $+/-$ & $+1-$ \\
\hline 3 & Light yellow & Pink & Mod. russet & Round to oblong & Deep & Poor \\
\hline 4 & Medium yellow & Dark brown & Light russet & Mostly oblong & $+/-$ & $+1-$ \\
\hline 5 & Dark yellow & Brown & Netted & Oblong & Intermediate & Fair \\
\hline 6 & Pink & Tan & Slightly netted & Oblong to long & $+/-$ & $+/-$ \\
\hline 7 & Red & Buff & Mod. smooth & Mostly long & Shallow & Good \\
\hline 8 & Blue & White & Smooth & Long & $+1-$ & $+1-$ \\
\hline 9 & Purple & Cream & Very smooth & Cylindrical & Very shallow & Excellent \\
\hline
\end{tabular}

Results from FL 2016, NM 2016, and ME 2015 were compiled and used to narrow the number of selections for additional evaluation down to 82 clones, based on their being selected at two or three locations.

Third year field generation in Maine (2016). Clones were planted in a randomized complete block design with two replications on 2 June 2016. A plot consisted of five plants of a clone at the same in-row and betweenrow spacing as in 2015. Common commercial practices were once again used. Plots were harvested on 29 Sept. 2016. The number of tubers and total weight of tubers per plot was recorded.

Statistical analysis. Correlations among traits across locations were calculated using the correlation procedure in SAS, version 9.2 (SAS Institute, Cary, NC). Yield data from each location were analyzed separately using the mixed models procedure in SAS. Clones were considered fixed effects and replications were considered random effects. The distribution of residuals from each location was fairly normal, but the error variances among locations were heterogeneous. Therefore, the data were not combined for further analysis. Least square means were generated for each clone and ranked within a location from highest $($ ranking $=1)$ to lowest.

\section{Results and Discussion}

First field generation in Maine (2014). From 14,035 clones initially planted in ME 2014,689 (4.9\% of the total) were initially selected. This represents a higher percentage than normal, which may be due to the number of selectors, the large amount of variation present within a family, the lack of defined selection criteria for the intense yellow-flesh creamer market, and/or the unique nature of the germplasm. Three two-person teams (inexperienced selectors paired with experienced selectors) went through the field making selections, bagging, and labeling clones. Unlike tetraploid families, which usually result from controlled crosses within market classes, variation for all tuber characteristics was much greater in the diploid open-pollinated families. For those with selection experience limited to traditional tetraploid market classes, the variation in tuber size, color, shape, and other characteristics in this diploid population, coupled with a lack of defined selection criteria for this new marketing niche, presented a wide array of possibilities. In the U.S. Department of
Agriculture-Agricultural Research Service's (USDA-ARS) tetraploid potato breeding populations, the normal selection percentage in the first field generation ranges from $2 \%$ to 3\% (Haynes et al., 2014).

Nine different skin colors were represented in the 689 original selections: 249 $(36.1 \%)$ were yellow, $158(22.9 \%)$ were red, $116(16.8 \%)$ were tan, $78(11.3 \%)$ were pink, $35(5.1 \%)$ were buff, $32(4.6 \%)$ were purple, $6(0.9 \%)$ were orange, $4(0.6 \%)$ were brown, and $11(1.6 \%)$ were bicolored (combinations of red or pink and tan or yellow).

Overall skin texture rating of the 689 original selections was 7.3 and ranged from 4 to 9 . Only one clone had a lightly russeted texture, five had a netted texture, and 76 were slightly netted. The rest were moderately smooth to very smooth. Because creamer potatoes are meant to be eaten either whole or halved with the skins on, smoother textures are more desirable.

Overall shape rating of the 689 original selections was 3.7 and ranged from 1 to 8 . Oblong shapes predominated (ratings $=4$ or $5,40 \%$ of the clones), followed by round shapes (ratings $=1$ or $2,31 \%$ of the clones) and long shapes (ratings $=7$ or $8,6 \%$ of the clones). The rest of the clones had variable shapes: $16 \%$ of the clones were round to oblong (rating $=3$ ) and $8 \%$ were oblong to long.

Overall eye depth rating of the 689 original selections was 5.2 and ranged from 3 to 9 . Intermediate eye depth predominated (rating = $5,49 \%$ of the clones), followed by moderately shallow (rating $=7,24 \%$ of the clones), deep (rating $=3,23 \%$ of the clones), and very shallow (rating $=9,3 \%$ of the clones).

Overall tuber appearance rating of the 689 original selections was 5.2 and ranged from 1 to 9 . Fair (rating $=5$ ) appearance predominated in $59 \%$ of the clones, $24 \%$ of the clones were rated with a good appearance (rating = 7 ), and $1 \%$ of the clones were rated with an excellent appearance (rating $=9$ ). The rest of the clones $(16 \%)$ were rated poor or very poor in appearance. The poor or very poor ratings were somewhat surprising given the selection criteria. However, they were probably representative of the different selection pressure applied by the selectors (some of whom had never selected within the diploid population before) and the postharvest evaluator, who had more than ten years' experience rating diploid populations.

Overall flesh color averaged 3.8 and ranged from white to dark yellow-orange:
$5.7 \%$ of the clones were white fleshed, $3.8 \%$ were cream fleshed, $6.8 \%$ were light-yellow fleshed, $71.6 \%$ were yellow fleshed, and $12.2 \%$ were dark-yellow to orange fleshed. Among the 44 orange-fleshed families, flesh color ranged from white to orange; only 30 of the 449 clones selected from the orangefleshed breeding nursery scored as orange fleshed, when they were all expected to be orange fleshed. Because foreign pollen in the orange-fleshed open-pollinated seed nursery was expected to be negligible due to the distance from the yellow-fleshed openpollinated seed nursey, it is more likely that many of the so-called orange-fleshed parents that went into that open-pollinated seed nursery were not recessive for the Zep 1 allele, and hence, those parents were either misclassified for flesh color or had high levels of zeaxanthin despite not having two copies of the Zep 1 allele. Levels of zeaxanthin can vary greatly among individual clones in this population (Lu et al., 2001). High levels of zeaxanthin impart an orange color to the flesh (Brown et al., 1993).

Discarding the clones with the shortest dormancy in each family had little or no effect on the mean or range of values for any of the traits measured: skin color, skin texture, tuber shape, tuber eye depth, tuber appearance, or tuber flesh color.

All but three selections had sprouted by 10 Dec. 2014 (78 d after harvest). Data ceased to be recorded after this time because seed was packed for shipping to FL and NM. The average number of days to sprouting for all 689 selections was $20 \mathrm{~d}$. Within 8 d of harvest, 182 selections had sprouted. Fifteen days after harvest, another 170 selections had sprouted. After discarding the clones with the shortest dormancy in each family, the average number of days to sprouting was only 25 d. Short dormancy is a characteristic of $p h u$, and longer dormancy of stn (Dodds and Paxman, 1962). Thompson et al. (1980) reported that the mean length of dormancy for $p h u$ and stn in their study was 20 and $75 \mathrm{~d}$ after harvest, respectively. Progeny from their parents had a mean length of dormancy of $47 \mathrm{~d}$, exactly midway between the two groups. They also found that additive genetic variance for tuber dormancy predominated; the narrow-sense heritability estimate for dormancy was 0.73 . No dormancy (i.e., tubers sprouting at harvest) was one of the negative selection criteria used in this study.

First year field evaluations in the south (FL 2015, NM 2015). Three hundred fifty-seven 
clones undergoing evaluation for the intense yellow-flesh creamer market were evaluated at two southern locations: Hastings, FL and Los Lunas, NM. These locations represented potential production sites with proximity to large Hispanic markets. Ratings in FL and NM were on a one- to four-plant plot basis, with seed tubers sourced from the ME 2014 single-plant harvest.

In general, tuber skin colors were similar across all three environments (Table 2). A common phenomenon in commercial redskinned potato cultivars is the tendency for the red-skin color to fade to pink under higher temperature production environments. One hundred forty-four clones had anthocyanin (pink, red, purple) -colored skin. Among these 144 clones, the two southern locations had slightly higher average skin color $(\mathrm{FL}=$ 2.6, $\mathrm{NM}=2.8)$ than $\mathrm{ME}(2.2)$, indicating a general tendency toward lighter skin color under higher temperature growing conditions, as expected. The correlations involving skin color among the locations were the highest correlations observed for any of the traits scored, ranging from 0.77 to 0.85 .

Tuber skin texture was more heavily netted in the southern states than in ME (Table 2). The development of skin russeting in normally smooth-skin varieties is known to occur (Yamaguchi et al., 1964) and results from an accumulation of periderm/skin layers in response to high soil temperatures (Ginzberg et al., 2009). Thus, the coarser texture in the southern states was not surprising. The correlations involving skin texture among locations were some of the lowest correlations observed for any of the traits scored, ranging from -0.03 to 0.11 . There was less variation for skin texture in ME than in either FL or NM, as evidenced by the fact that the variance for skin texture in $\operatorname{ME}\left(\sigma^{2}=\right.$ $0.59)$ was less than one-third that in FL $\left(\sigma^{2}=\right.$ $3.12)$ or NM $\left(\sigma^{2}=2.00\right)$. This finding indicates that there is genetic variation in this germplasm for skin texture response to higher temperatures.

Tuber shape was generally round to oblong, although there were some clones with a long tuber shape (Table 2). Shape averaged across locations gave 73 round (average shape $\leq 2$ ), 239 round to oblong $(2<$ average shape $\leq 5)$, and 45 oblong to long (average shape $>5$ ). Several studies have found that round tuber shape is dominant over long (de Jong and Burns, 1993; de Jong and Rowe, 1972), and this finding has been verified by genetic mapping (LindqvistKreuze et al., 2015; Vaneck et al., 1994) where the round gene, designated $R o$, has been mapped to chromosome 10 . The correlations involving tuber shape among the locations were moderate, ranging from 0.50 to 0.67 . However, the variation for tuber shape was similar across all locations.

Tuber eye depth was generally intermediate to shallow, the average ranging from 5 to 7 (Table 2). Eye depth tended to be rated deeper in ME than in either FL or NM. Whether this rating is due to evaluator differences or represents an environmental

Table 2. Average ratings for tuber skin color, texture, shape, eye depth, overall appearance, and flesh color for 357 clones evaluated in Hastings, FL in 2015; Los Lunas, NM in 2015; and Presque Isle, ME in 2014; and the correlations among traits at two locations.

\begin{tabular}{|c|c|c|c|c|c|c|}
\hline \multirow[b]{2}{*}{ Trait } & \multicolumn{3}{|c|}{ Avg } & \multicolumn{3}{|c|}{ Correlations } \\
\hline & FL & NM & ME 2014 & FL-NM & FL-ME & NM-ME \\
\hline Skin color & 4.8 & 4.7 & 4.9 & $0.77 * * *$ & $0.82 * * *$ & $0.85 * * *$ \\
\hline Texture & 5.2 & 4.8 & 7.4 & $-0.03 \mathrm{NS}$ & $0.11^{*}$ & $0.07 \mathrm{NS}$ \\
\hline Shape & 3.1 & 3.3 & 3.9 & $0.50 * * *$ & $0.67 * * *$ & $0.61 * * *$ \\
\hline Eye depth & 6.5 & 6.9 & 5.1 & $0.14 *$ & $0.30 * * *$ & $0.12 *$ \\
\hline Appearance & 5.4 & 5.0 & 5.3 & $0.00 \mathrm{NS}$ & $0.10 \mathrm{NS}$ & $-0.06 \mathrm{NS}$ \\
\hline Flesh color & 3.5 & 3.4 & 3.7 & $0.49 * * *$ & $0.56 * * *$ & $0.50 * * *$ \\
\hline Dormancy (d) & 24 & - & 20 & - & $0.31 * * *$ & - \\
\hline
\end{tabular}

*Significant at $P<0.05$; ***significant at $P<0.0001$; nS $=$ not significant; - indicates not available.

component is unknown. Only one study was found in the literature that suggested that eye depth could be efficiently selected in two vastly different environments (Johansen et al., 1965); but details were lacking in the abstract, and the full report was never published. Several studies have shown that deep eye depth is dominant to shallow ( $\mathrm{Li}$ et al., 2005; Mosquera et al., 2009). The correlations involving tuber eye depth among the locations were low to moderate, ranging from 0.12 to 0.30 . In general, the diploid species phu and stn have deep eyes, so the moderateto-shallow eyes recorded here are evidence of the success in selecting against deep eyes in the North Carolina State University (from 1966 to 1986) and USDA-ARS (from 1987 to present) breeding programs over the years.

Average tuber appearance ratings were similar across locations, ranging from 5.0 to 5.4 (Table 2). However, there was no correlation among the ratings at any of the locations. Neele et al. (1991) reported that selection on plant appearance (based on visual scoring of foliage, stolons, and tubers) was unreliable in the first two clonal generations due to significant genotype $\times$ environment interactions and high error variances. ME ratings were based on a one-hill plot, whereas FL and NM ratings were based on a maximum of four-hill plots

Average flesh color ratings evaluated at harvest were similar across locations, ranging from 3.4 to 3.7 (Table 2). Average ratings were slightly darker in ME than in FL or NM. This finding may be due to evaluator differences or lighting differences while scoring. ME tubers were scored under fluorescent light in storage. In FL, tubers were scored in a barn under fluorescent lamp light. Genotype $\times$ environment interactions for flesh color, as measured objectively by a colorimeter, are known to be statistically significant, but of little practical significance (Haynes et al., 1996). Yellow-flesh intensity in potato tubers is positively correlated with total carotenoid content $(r=0.83)$ (Lu et al., 2001), so many of these selections are expected to have higher levels of carotenoids than what is found in commercial tetraploid cultivars.

The average number of days to sprouting for all clones harvested in FL was $24 \mathrm{~d}$. This number is in close agreement with the ME 2014 first field generation. However, the range in FL, from 16 to 152 + days, was
Table 3. Correlations among the same traits at the same location in different years.

\begin{tabular}{|c|c|c|c|}
\hline & $\mathrm{ME}$ & FL & NM \\
\hline Trait & 2014-15 & $2015-16$ & 2015-16 \\
\hline Skin color & $0.67 * * *$ & $0.74 * * *$ & $0.73 * * * *$ \\
\hline Texture & $0.22 * * *$ & $0.06 \mathrm{NS}$ & $0.15 \mathrm{NS}$ \\
\hline Shape & $0.78 * * *$ & $0.65 * * *$ & $0.67 * * *$ \\
\hline Eye depth & $0.47 * * *$ & $0.31 * *$ & - \\
\hline Appearance & $0.25 * * *$ & $0.24 *$ & $0.01 \mathrm{NS}$ \\
\hline Flesh color & - & $0.55 * * *$ & $0.51 * * *$ \\
\hline
\end{tabular}

*Significant at $P<0.05$; **significant at $P<0.01$; ***significant at $P<0.0001 ;$ NS $=$ not significant; indicates not available.

more than twice as great as in Maine in 2014. Discounting the clones that had not sprouted by the end of the observation period, the correlation between days to sprouting in ME 2014 and FL 2015 was $0.31(P<0.0001)$. The moderately low correlation was not surprising, because warmer temperature growing environments are known to shorten dormancy (Susnoschi, 1981). What was surprising was to find that five clones had a dormancy greater than $152 \mathrm{~d}$. NM did not evaluate for days to sprouting in 2015 .

FL selected 101 clones to continue evaluating, NM selected 28, and of those, only four clones were selected at all three locations.

Second field generation in Maine (2015). Seven clones were lost due to rotting in storage between the first and second field generation in ME. A far larger loss occurred in the field in 2015 when 123 clones were lost due to a severe soft rot infestation brought on by an extremely wet growing season.

As expected, correlations of tuber skin color $(r=0.67, P<0.001)$ and shape $(r=$ $0.78, P<0.001)$ between the first and second field generation in ME 2014 and 2015 were high (Table 3). Correlationsof skin texture $(r=0.22, P<0.001)$, eye depth $(r=0.21, P<$ $0.01)$, and tuber appearance $(r=0.25, P<$ $0.001)$ between the two years were low. The correlation of days to sprouting between $\mathrm{ME}$ 2014 and ME 2015 was only moderate $(r=$ $0.39, P<0.0001)$. The average number of days to sprouting in 2014 was 29 for the 227 clones grown in common both years, whereas the average number of days to sprouting in 2015 was 51 . There may be several reasons for this result: the first observation on sprouting in ME 2015 was nearly three weeks later than in 2014 due to harvesting demands; sufficient seed was available to enable 
observations on sprouting to continue nearly two months longer in 2015; and wet conditions or other environmental factors and/or seed size may also have affected tuber dormancy.

Of the 227 clones that survived the 2015 growing season in ME, 125 were selected from the second field generation (Table 4). Thirty-seven $(16.3 \%)$ of these were selected in both FL 2015 and ME 2015. The percentages for selected clones between ME and FL were higher than an earlier study (9.7\%) looking at early generation selection in tetraploid clones undergoing evaluation for more traditional markets (Haynes et al., 2012). FL and ME 2015 both agreed to discard 70 clones $(30.8 \%)$, which was lower than in the previously mentioned study where $55.5 \%$ of the clones were discarded (Haynes et al., 2012). FL and ME 2015 disagreed on the fate of the remaining 120 clones (52.9\%), which was higher than in the previously mentioned study where they disagreed on $34.8 \%$ of the clones. These discrepancies may reflect differences in ploidy level between the two studies: tetraploids are generally considered to be better buffered against environmental variables than diploids due to their greater allelic diversity. It is also possible, however, that the higher percentage of disagreement between $\mathrm{ME}$ and FL may be a result of dealing with developing different selection criteria for this new marketing niche.

In contrast, only $14(6.2 \%)$ clones were selected in both NM and ME 2015 (Table 4). $\mathrm{NM}$ and ME both agreed to discard 97 clones $(42.7 \%)$ and disagreed on the fate of the remaining 116 clones $(51.1 \%)$. The lower percentage selected may indicate greater environmental sensitivity in this germplasm. This was also the first year that NM had grown potatoes, and so the low saved percentage may reflect learning how to grow and evaluate a new crop.

Only six clones were selected in both FL and NM 2015. FL and NM 2015 both agreed to discard 144 clones and disagreed on the fate of the remaining 77 clones.

It is interesting that the greatest agreement (both agree to save, and both agree to discard), $66.0 \%$, was between the two southern locations (FL, NM). The least agreement at $47.1 \%$ was between FL and ME, two programs with a long history of collaboration. The differences in agreement between these locations were significant $\left(\chi^{2}=20.01\right.$, $P<0.001$ ).

Second year field evaluations in the south (FL 2016, NM 2016). Eighty-two clones were evaluated in replicated trials in the southern

Table 4. Percent agreement among ME (in 2015), FL (in 2015), and NM (in 2015) selectors for 227 clones evaluated at each location.

\begin{tabular}{lrccc}
\hline & Agree & & Agree & \\
\cline { 2 - 3 } \cline { 5 - 5 } Locations & Save & & Discard & Disagree \\
\hline ME and FL & 16.3 & & 30.8 & 52.9 \\
ME and NM & 6.2 & & 42.7 & 51.1 \\
FL and NM & 2.6 & & 63.4 & 33.9 \\
\hline
\end{tabular}

states in 2016. Compared with the clones in the first year of field evaluation in FL, this subset of selected clones in the second year in FL generally averaged lighter skin texture (7.3 vs. 5.2$)$, slightly better appearance ( 6.0 vs. 5.3), and had longer dormancy (40 vs. 24 d). The averages for other characteristics were similar between the two years. High correlations were observed between years for skin color $(r=0.74, P<0.0001)$ and tuber shape $(r=0.65, P<0.0001)$; moderate-tolow correlations were observed for eye depth $(r=0.31, P<0.001)$ and appearance $(r=$ $0.24, P<0.05$ ); and there was a negative correlation for days to sprouting $(r=-0.25$, $P<0.05)$ (Table 3 ). There was no correlation for skin texture between years.

Compared with the clones in the first yield of field evaluations in NM, this subset of selected clones in the second year in NM generally averaged slightly lighter skin texture (5.6 vs. 4.8). The averages of other characteristics were similar between the two years. Moderate-to-high correlations were observed between years for skin color $(r=$ $0.73, P<0.0001)$, tuber shape $(r=0.67, P<$ $0.0001)$, and flesh color $(r=0.51, P<0.0001)$ (Table 3). No correlations were observed for skin texture or appearance. NM did not evaluate eye depth in 2016.

Thus, these selections maintained their phenotypic diversity for most traits. Diversity in skin color, flesh color, and tuber shape could conceivably be advantageous from a marketing standpoint in allowing the development of multiple cultivars to either fill different niches or be combined into an appealing mixture of cultivars. For the locations that evaluated length of dormancy both years, clones had longer dormancy the second year. It is difficult to assign a single explanation for these differences because in ME the first year field generation was propagated from greenhouse-produced mini-tubers, whereas the second year field generation was propagated from fieldproduced whole seed. However, in FL both the first and second year field evaluations were propagated from field-produced whole seed. Thus differences in length of dormancy may also be due a carry-over effect of the seed growing environment. Such effects on other traits in potatoes have been reported (Hutchinson et al., 2014; Madec and Perennec 1959).

Third year field data in Maine (2016). Growing conditions in ME in 2016 were nearly ideal for potatoes, with warm days, cool nights, and adequate rainfall. The average high air temperatures for June, July, and Aug. were $22.3,25.2$, and $25.0^{\circ} \mathrm{C}$, while the average low air temperatures were 10.5, 13.9, and $13.5^{\circ} \mathrm{C}$. Rainfall totaled $73.2,148.6$, and $119.8 \mathrm{~mm}$, respectively.

The 2016 data from the ME harvest included not only tuber yield, but also the number of tubers per five-plant plot. There were significant differences among the clones for average number of tubers per plot, which ranged from 28 to 182 . There were also significant differences among the clones for average weight of individual tubers, which ranged from $15 \mathrm{~g}$ to $68 \mathrm{~g}$. Considerable progress has been made in increasing the size of tubers in the phu-stn population. Thompson et al. (1980) reported an average tuber weight of $2.6 \mathrm{~g}$ for $p h u$ and $2.0 \mathrm{~g}$ for stn. In contrast, the average tuber weight in ME 2016 was $33 \mathrm{~g}$. Gautney and Haynes (1983) reported a mean yield per hill, in their phu-stn population, of $130.3 \mathrm{~g}$. In contrast, the mean yield per hill in ME 2016 was $592 \mathrm{~g}$.

There was a significant negative correlation $(r=-0.62, P<0.0001)$ between number of tubers and weight of tubers. A similar trend has been observed at the tetraploid level (Bhagowati et al., 2002; Gan et al., 2013; Gopal et al., 1994; Sanwal et al., 2003).

Statistical analysis of yield trial data from all locations. Yields in 2016 were greatest in ME, followed by FL, with the lowest yields in NM. The average plot yield in ME 2016 was $2960 \mathrm{~g}$, ranging from 1078 to $5153 \mathrm{~g}$. The average plot yield in FL 2016 was 2383 g, ranging from 622 to $4944 \mathrm{~g}$. The average plot yield in NM 2016 was $461 \mathrm{~g}$, ranging from 119 to $874 \mathrm{~g}$. The greater clonal yields in ME may be due either to the cooler growing season as compared with the southern locations and/or to better adaptation to the longer day growing conditions in ME as compared with the southern locations. Potato was a new crop for personnel at New Mexico's Los Lunas Agricultural Science Center, so optimum production protocols have not yet been developed for this area of the state. The lower plot yields in NM may be due to environmental conditions not conducive to production of these potatoes, or the result of optimal inputs not yet determined for this crop in Los Lunas, NM.

There were significant differences among clones for total yield at each location in 2016 . Least square mean yields were ranked from highest to lowest at each location. Four clones were ranked in the top 20 at all three locations. Eighteen clones consistently yielded in the top half of the rankings. Two clones yielded well in the south but poorly in the north, indicating that they might have some tolerance to heat. Two clones yielded poorly in the south but well in the north, indicating that they might be sensitive to heat stress. Twenty clones consistently yielded in the lower half of the rankings. Pictures of some of the better-yielding clones are shown in Fig. 1.

Thus far, attempts to introgress the intense yellow-flesh trait, and hence high carotenoid levels, from diploid potatoes to tetraploid potatoes have met with limited success (Haynes et al., 2011). Tetraploid germplasm with higher levels of carotenoids have been obtained, but they still fall far short of the concentrations that have been recorded in intense yellow- and orange-fleshed diploids.

\section{Conclusions}

There are three main disadvantages to using the South American cultivated groups Phureja and Stenotomum in the United 
A

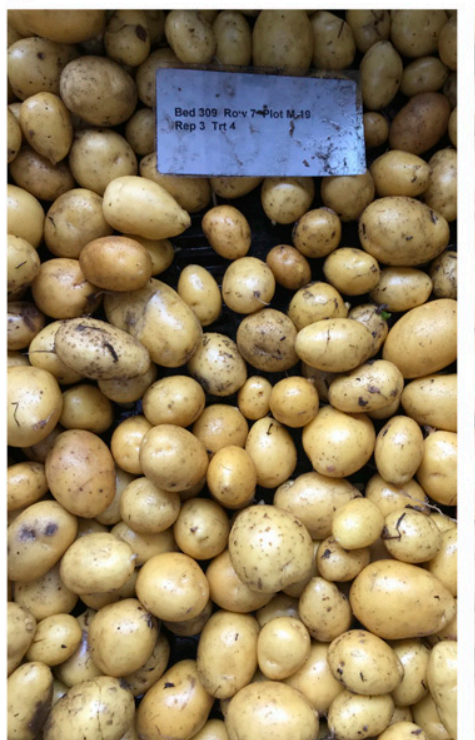

C

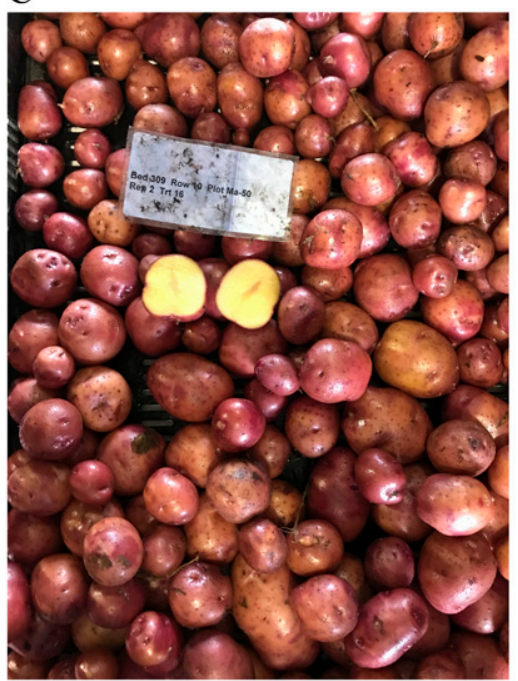

B

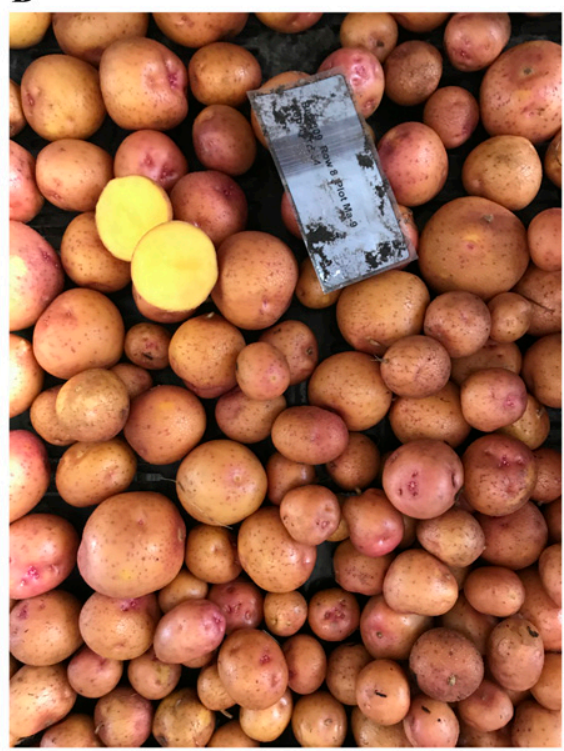

D

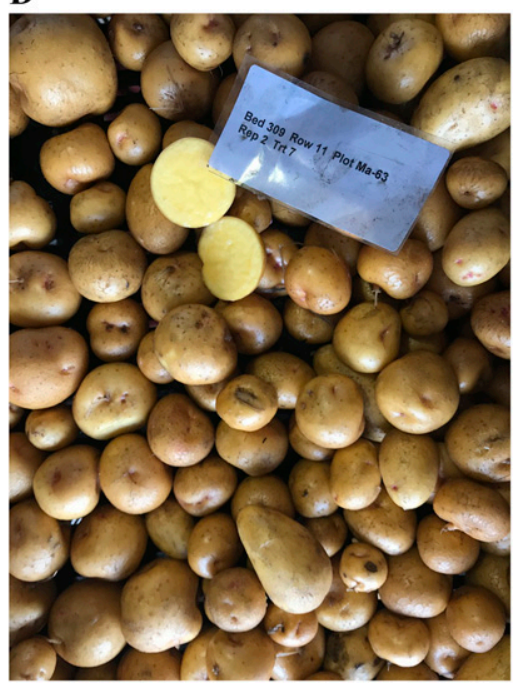

Fig. 1. Pictures of some of the diploid creamer potatoes from the diploid hybrid Solanum tuberosum groups Phureja and Stenotomum population for the intense yellow flesh being evaluated.

States: 1) they are short-day adapted, 2) their tubers have deep eyes, and 3) their tubers have no or very short dormancy. Our previous breeding efforts have addressed the first two objections. Average tuber size has increased more than 10 -fold and average plant yield has increased more than 4.5-fold through recurrent selection for long-day adaptation. Individual clones within this longday adapted population can be identified that are better than these population means. Although deep eyes are a dominant trait, the population has been heavily selected for shallow eyes, as can be seen in the accompanying pictures (Fig. 1). Variation for tuber dormancy in the population suggests genetic improvements can be obtained in lengthening tuber dormancy.

A hybrid diploid population between South American cultivated groups Phureja and Stenotomum was evaluated in one northern and two southern locations to identify possible genotypes for their poten- tial as intense yellow-flesh creamer varieties in the United States. The population has been adapted to long-day growing conditions while maintaining phenotypic diversity for tuber skin color, flesh color, and shape. Correlations involving tuber skin color and shape between years were generally high at all locations. In general, skin colors involving anthocyanins were slightly lighter in color in the south and skin textures were slightly more coarse. Tuber dormancy was generally short, but some long dormant clones were identified. Breeding efforts in the future need to be undertaken to extend the dormancy period of these clones to enhance their marketability.

\section{Literature Cited}

Akbaraly, N.T., H. Faure, V. Gourlet, A. Favier, and C. Berr. 2007. Plasma carotenoid levels and cognitive performance in an elderly population: Results of an EVA study. J. Gerontol. A Biol. Sci. Med. Sci. 62:308-316.
Bhagowati, R.R., M. Saikia, and D. Sut. 2002. Variability, heritability, genetic advance and character association in true potato seed (TPS) populations. J. Agr. Sci. Soc. North East India 15:119-122.

Blessington, T., M.N. Nzaramba, D.C. Scheuring, A.L. Hale, L. Reddivari, and J.C. Miller, Jr. 2010. Cooking methods and storage treatments of potatoes: Effects on carotenoids, antioxidant activity, and phenolics. Amer. J. Potato Res. 87:479-491.

Brown, C.R., C.G. Edwards, C.-P. Yang, and B.B. Dean. 1993. Orange flesh trait in potato: Inheritance and carotenoid content. J. Amer. Soc. Hort. Sci. 118:145-150.

Brown, C.R., T.S. Kim, Z. Ganga, K. Haynes, D. De Jong, M. Jahn, I. Paran, and W. De Jong. 2006. Segregation of total carotenoid in high level potato germplasm and its relationship to beta-carotene hydroxylase polymorphism. Amer. J. Potato Res. 83:365-372.

Burgos, G., W. Amoros, E. Salas, L. Muñoa, P. Sosa, C. Díaz, and M. Bonierbale. 2012. Carotenoid concentrations of native Andean potatoes as affected by cooking. Food Chem. 133:1131-1137

Clevidence, B., K. Haynes, D. Rao, and J. Novotny. 2005. Effect of cooking method on xanthophyll content of yellow-fleshed potato. United States Japan Natural Resources Protein Panel 34:280 284.

de Jong, H. and V.J. Burns. 1993. Inheritance of tuber shape in cultivated diploid potatoes. Amer. Potato J. 70:267-283.

de Jong, H. and P.R. Rowe. 1972. Genetic markers in inbred clones of cultivated diploid potatoes. Potato Res. 15:200-208.

Diretto, G., R. Tavazza, R. Welsch, D. Pizzichini, F. Mourgues, V. Papacchioli, P. Beyer, and G. Giuliano. 2006. Metabolic engineering of potato tuber carotenoids through tuber-specific silencing of lycopene epsilon cyclase. BMC Plant Biol. 6:13.

Dodds, K.S. and G.J. Paxman. 1962. The genetic system of cultivated diploid potatoes. Evolution 16:154-167.

Feeney, J., N. O’Leary, R. Moran, A.M. O'Halloran, J.M. Nolan, S. Beatty, I.S. Young, and R.A. Kenny. 2017. Plasma lutein and zeaxanthin are associated with better cognitive function across multiple domains in a large population-based sample of older adults: Findings from the Irish longitudinal study on aging. J. Gerontol. A Biol. Sci. Med. Sci. 72:1431-1436.

Gan, L., X. Yu, Z. Yu, M. Meng, and Z. Zhang. 2013. A study on main agronomic traits of yield and quality of clone lines of Solanum tuberosum hybrids F1. Acta Prataculturae Sinica 22:312-318.

Gautney, T.L. and F.L. Haynes. 1983. Recurrent selection for heat tolerance in diploid potatoes (Solanum tuberosum subsp. phureja and stenotomum). Amer. Potato J. 60:537-542.

Ginzberg, I., G. Barel, R. Ophir, E. Tzin, Z. Tanami, T. Muddarangappa, W. de Jong, and E. Fogelman. 2009. Transcriptomic profiling of heat-stress response in potato periderm. J. Expt. Bot. 60:4411-4421.

Gopal, J., P.C. Gaur, and M.S. Rana. 1994. Genetic variability and nature of intergeneration association in yield and its components in potato. Indian J. Genet. Plant Breed. 54:170-174.

Haynes, F.L. 1972. The use of cultivated diploid Solanum species in potato breeding, p. 100 110. In: E.R. French (ed.). Prospects for the potato in the developing world. Centro Internacional de la Papa, Lima, Peru. 
Haynes, K.G., J.B. Sieczka, M.R. Henninger, and D.L. Fleck. 1996. Clone $\times$ environment interactions for yellow-flesh intensity in tetraploid potatoes. J. Amer. Soc. Hort. Sci. 121:175-177.

Haynes, K.G. 2008. Heritability of chip color and specific gravity in a long-day adapted Solanum phureja-S. stenotomum population. Amer. J. Potato Res. 85:361-366.

Haynes, K.G., B.A. Clevidence, D. Rao, and B.T. Vinyard. 2011. Inheritance of carotenoid content in tetraploid $\times$ diploid potato crosses. J. Amer. Soc. Hort. Sci. 136:265-272.

Haynes, K.G., D.M. Gergela, C.M. Hutchinson, G.C. Yencho, M.E. Clough, M.R. Henninger, D.E. Halseth, E. Sandsted, G.A. Porter, and P.C. Ocaya. 2012. Early generation selection at multiple locations may identify potato parents that produce more widely adapted progeny. Euphytica 186:573-583.

Haynes, K.G., X. Qu, and B.J. Christ. 2014. Two cycles of recurrent maternal half-sib selection reduce foliar late blight in a diploid hybrid Solanum phureja-S. stenotomum population by two-thirds. Amer. J. Potato Res. 91:254-259.

Hawkes, J.G. 1988. The evolution of cultivated potatoes and their tuber-bearing wild relatives. Die Kulturpflanze 36:189-208.

Huamán, Z. and D.M. Spooner. 2002. Reclassification of landrace populations of cultivated potatoes (Solanum sect. Petota). Amer. J. Bot. 89:947-965.

Hutchinson, P.J.S., J. Felix, and R. Boydston. 2014. Glyphosate carryover in seed potato: Effects on mother crop and daughter tubers. Amer. J. Potato Res. 91:394-403.

Johansen, R.H., J.C. Miller, D.W. Newsom, and J.F. Fontenot. 1965. The effect of environment on the genetic behavior of potato progenies. Amer. Potato J. 42:263-264 (abstr.).

Johnson, E.J. 2012. A possible role for lutein and zeaxanthin in cognitive function in the elderly. Amer. J. Clin. Nutr. 95:1161S-1165S.

Kaspar, K.L., J.S. Park, C.R. Brown, B.D. Mathison, D.A. Navarre, and B.P. Chew. 2011. Pigmented potato consumption alters oxidative stress and inflammatory damage in men. J. Nutr. 141:108111.

Kotiková, Z., M. Šulc, J. Lachman, V. Pivec, M. Orsák, and K. Hamouz. 2016. Carotenoid profile and retention in yellow-, purple- and red-fleshed potatoes after thermal processing. Food Chem. 197:992-1001.
Li, X.Q., H. de Jong, D.M. DeJong, and W.S. de Jong. 2005. Inheritance and genetic mapping of tuber eye depth in cultivated diploid potatoes. Theor. Appl. Genet. 110:1068-1073.

Lindqvist-Kreuze, H., A. Khan, E. Salas, S. Meiyalaghan, S. Thomson, R. Gomez, and M. Bonierbale. 2015. Tuber shape and eye depth variation in a diploid family of Andean potatoes. BMC Genet. $16: 57$.

Lu, W., K. Haynes, E. Wiley, and B. Clevidence. 2001. Carotenoid content and color in diploid potatoes. J. Amer. Soc. Hort. Sci. 126:722-726.

Madec, P. and P. Perennec. 1959. The part played by leaves and the mother tuber respectively in tuberisation of the potato. Eur. Potato J. 2:2249.

McCord, P., L. Zhang, and C. Brown. 2012. The incidence and effect on total tuber carotenoids of a recessive zeaxanthin epoxidase allele ( $\mathrm{Zep}$ 1) in yellow-fleshed potatoes. Amer. J. Potato Res. 89:262-268.

Mosquera, V., H.A. Mendoza, V. Villagomez, and D. Tay. 2009. Plant and tuber trait inheritance in autotetraploid potatoes $(4 \mathrm{x})$. Proc. Tri. Symp. Intl. Soc. Trop. Root Crops. 15:17-20.

Neele, A.E., H.J. Nab, and K.M. Louwes. 1991 Components of visual selection in early clonal generations of a potato breeding programme. Plant Breed. 106:89-98.

Potatoes USA. 2018. The perfect potato: An overview of fresh potato types for professional chefs. 15 Aug. 2018. <http://www.potatogoodness. com/wp-content/uploads/2016/08/PotatoTypes-Brochure.pdf>.

Sanwal, S.K., R.D. Bhutani, S.C. Khurana, and S.P. Yadav. 2003. Associations of tuber yield with some important physiological parameters with reference to crop duration in potato (Solanum tuberosum L.). Haryana J. Hort. Sci. 32:107110.

Snodderly, D.M. 1995. Evidence for protection against age-related macular degeneration by carotenoids and antioxidant vitamins. Amer. J. Clin. Nutr. 62(Suppl 1):448S-1461S.

Sommerburg, O., J.E.E. Keunen, A.C. Bird, and F.J.G.M. van Kuijk. 1998. Fruits and vegetables that are sources of lutein and zeaxanthin: The macular pigments in human eyes. Brit. J. Ophthalmol. 82:907-910.

Susnoschi, M. 1981. Seed potato quality as influenced by high-temperatures during the growth period. 2. Sprouting pattern in several cultivars in response to storage-temperature. Potato Res. 24:381-388
Thompson, P.G., F.L. Haynes, and R.H. Moll. 1980. Estimation of genetic variance components and heritability for tuber dormancy in diploid potatoes. Amer. Potato J. 57:3946.

Tierno, R., D. Hornero-Méndez, L. Gallardo-Guerrero, R. López-Pardo, and J.I. Ruiz de Gallareta. 2015. Effect of boiling on the total phenolic, anthocyanin and carotenoid concentrations of potato tubers from selected cultivars and introgressed breeding lines from native potato species. J. Food Compos. Anal. 41:58-65.

USDA, ERS. 2013. Tomatoes and potatoes are the most commonly consumed vegetables. 15 Aug. 2018. <https://www.ers.usda.gov/data-products/ chart-gallery/gallery/chart-detail/?chartId=77042>.

USDA, ERS. 2018. U.S. per capita use of fresh and processing vegetables, dry pulse crops, and potatoes; cash receipts; U.S. vegetable trade. 15 Aug. 2018. <https://www.ers.usda.gov/webdocs/ DataFiles/88551/General.pdf?v=43199>.

Vaneck, H.J., J.M.E. Jacobs, P. Stam, J. Ton, W.J. Stiekema, and E. Jacobsen. 1994. Multiple alleles for tuber shape in diploid potato detected by qualitative and quantitative geneticanalysis using RFLPs. Genetics 137:303-309.

Vishwanathan, R., A. Iannaccone, T.M. Scott, S.B. Kritchevsky, B.J. Jennings, G. Carboni, G. Forma, S. Satterfield, T. Harris, K.C. Johnson, W. Schalch, L.M. Renzi, C. Rosano, and E.J. Johnson. 2014. Macular pigment optical density is related to cognitive function in older people. Age and Ageing 43:271-275.

Wolters, A.M.A., J.G.A.M.L. Uitdewilligen, B.A. Kloosterman, R.C.B. Huttten, R.G.F. Visser, and H.J. vanEck. 2010. Identification of alleles of carotenoid pathway genes important for zeaxanthin accumulation in potato tubers. Plant Mol. Biol. 73:659-671.

Yamaguchi, M., H. Timm, and A.R. Spurr. 1964. Effects of soil temperature on growth and nutrition of potato plants and tuberization, composition, and periderm structure of tubers. Proc. Amer. Soc. Hort. Sci. 84:412-423.

Zotarelli, L., P.D. Roberts, P.J. Dittmar, S.E. Webb, S.A. Smith, B.M. Santos, and S.M. Olson. 2012. Potato production in Florida, p. 243-259. In: S.M. Olson and B.M. Santos (eds.). Vegetable production handbook for Florida 2012-2014. University of Florida Institute of Food and Agricultural Sciences, Gainesville, FL. 